\title{
Acute Renal Failure, Microangiopathic Haemolytic Anemia, and Secondary Oxalosis in a Young Female Patient
}

\author{
Karolina M. Stepien, ${ }^{1}$ Peter Prinsloo, ${ }^{1}$ Tony Hitch, ${ }^{1}$ \\ Thomas A. McCulloch, ${ }^{2}$ and Rebecca Sims ${ }^{3}$ \\ ${ }^{1}$ Clinical Pathology Department, Nottingham University Hospitals Trust, Nottingham NG5 1PB, UK \\ ${ }^{2}$ Department of Histopathology, Nottingham University Hospitals Trust, Nottingham NG5 1PB, UK \\ ${ }^{3}$ Renal Unit, Nottingham University Hospitals Trust, Nottingham NG5 1PB, UK
}

Correspondence should be addressed to Karolina M. Stepien, kstepien@doctors.org.uk

Received 8 February 2011; Revised 12 April 2011; Accepted 6 May 2011

Academic Editor: David B. Kershaw

Copyright (C) 2011 Karolina M. Stepien et al. This is an open access article distributed under the Creative Commons Attribution License, which permits unrestricted use, distribution, and reproduction in any medium, provided the original work is properly cited.

\begin{abstract}
A 29-year old female presented with a one-week history of vomiting, diarrhoea, abdominal pain, and headache. On admission, she had acute renal failure requiring dialysis. Tests revealed a hemolytic anemia with thrombocytopenia. An initial diagnosis of thrombotic thrombocytopenic microangiopathy was made and plasma exchange was instigated. However, renal biopsy did not show thrombotic microangiopathy but instead revealed acute kidney injury with mild tubulointerstitial nephritis and numerous oxalate crystals, predominantly in the distal tubules. The patient had been taking large doses (>1100 mg daily) of vitamin C for many months. She also gave a history of sclerotherapy using injections of an ethylene glycol derivative for superficial leg veins. The patient completed five sessions of plasma exchange and was able to discontinue dialysis. She eventually achieved full renal recovery. She has now discontinued sclerotherapy and vitamin supplementation.
\end{abstract}

\section{Case}

A 29-year-old female patient was transferred into the Renal Unit with acute renal failure requiring emergency dialysis. She had presented to a peripheral hospital two days previously, reporting 7 days of frequent vomiting with possible coffee grounds, two episodes of nonbloody diarrhoea, epigastric pain, thirst, and reduced urine output. The patient had headache for two days prior to admission. Past medical history included one normal pregnancy, one ectopic pregnancy, and a miscarriage, as well as menorrhagia. She had no significant family history apart from possible cases of kidney stones and was taking oral contraceptive pill. Three months prior to the illness, her urea and creatinine had been routinely checked and were within normal reference ranges, $5.3 \mathrm{mmol} / \mathrm{L}(14.8 \mathrm{mg} / \mathrm{dL})$ and $70 \mu \mathrm{mol} / \mathrm{L}$ $(0.79 \mathrm{mg} / \mathrm{dL})$, respectively.

On transfer, she was alert, oriented, and hemodynamically stable. Her blood pressure 130/90, pulse 72 beats/min regular, and oxygen saturations were $98 \%$ on air, with a respiratory rate of 16 breaths/minute. She was apyrexial.
Urine output was $<15 \mathrm{mls} / \mathrm{hr}$ and she appeared dehydrated despite aggressive pretransfer intravenous fluid therapy at the referring hospital. Clinical examination was unremarkable apart from localised epigastric tenderness. There were no purpura, and full neurological examination was normal.

On admission, blood tests revealed a creatinine of $1815 \mu \mathrm{mol} / \mathrm{L}(21 \mathrm{mg} / \mathrm{dL})$, urea of $55 \mathrm{mmol} / \mathrm{L}(154 \mathrm{mg} / \mathrm{L})$, and potassium was $5.1 \mathrm{mmol} / \mathrm{L}$ and $\mathrm{pH} 7.35$. Hemoglobin was $6.3 \mathrm{~g} / \mathrm{dL}$, platelets $84 \times 10^{-9} / \mathrm{L}$, and lactate dehydrogenase (LDH) $2110 \mathrm{U} / \mathrm{L}$ (220-450). Haptoglobin was $<0.30 \mathrm{~g} / \mathrm{L}$ $(0.30-2.00)$ and absolute reticulocyte count $62 \times 10^{-9}(10-$ $100)$. Urine microscopy revealed RBC 52/uL (0-44), and protein to creatinine ratio was $113 \mathrm{mg} / \mathrm{mmol}$. A clinical diagnosis of hemolytic uremic syndrome/thrombotic thrombocytopenic purpura (HUS-TTP) was made. Dialysis was instigated after biochemistry and urine output failed to respond to hydration to euvolemia over the subsequent 24 hours.

On day 2, a blood film was obtained. It showed numerous red cell fragments ( $8 \%$ of normal cells), acanthocytes, polychromasia, helmet cells and neutrophilia. Coombs test was negative. A course of plasma exchange was initiated 
using 1.2 plasma volume exchanges [1] against pooled donor solvent-treated human plasma solution (Octaplas) and variable proportions of fresh frozen plasma (FFP). An encouraging response to the initial exchanges was seen with increase in urine output and rapid reduction in LDH (see Table 1).

Possible triggers of HUS-TTP were considered. The patient had been taking the combined oral contraceptive pill. Serum BHCG pregnancy test was negative. C3 and C4 complement levels were normal with negative double stranded DNA and antiphospholipid antibodies. Other autoantibodies were negative. Virology and immunology tests for blood-borne viruses, immunoglobulin levels and serum electrophoresis, were all negative or within reference ranges. A stool sample was negative for E. coli 0157. Laboratory test for ADAMTS13 (AD integrin-like and metalloproteinase with thrombospondin type 13 motifs) activity was $100 \%(60-133 \%)$ analysed by Fluorescence Resonance Energy Transfer Assays. The normal activity of ADAMTS13 was against the diagnosis of TTP.

The patient reported continued epigastric pain. Serum amylase and lipase were elevated at $175 \mathrm{U} / \mathrm{L}(<100)$ and 1047 U/L (<300), respectively. Gastroscopy was undertaken on day 4 to exclude upper gastrointestinal bleed. This showed mild gastritis only. Samples for Helicobacter pylori were negative. On the same day, an ultrasound scan of the abdomen showed no intra-abdominal abnormality and both kidneys to be normal in size and structure and Doppler assessed renal blood flow.

Renal biopsy could not be performed until four days into the treatment course of plasma exchange. No evidence of thrombotic microangiopathy was present. The biopsy showed an acute tubulointerstitial pathology characterised by focal, but marked, acute tubular injury (Figure 1(a)), with cell sloughing and a mild tubulointerstitial nephritis (Figure 1(b)). Additionally, the presence of numerous oxalate crystals within both the tubular lumina and the tubular epithelial cells was confirmed under polarized light (Figures 2(a) and 2(b)). The distal tubules appeared more affected than the proximal ones. There was no evidence of a glomerulonephritis or any significant vascular pathology.

The various causes of oxalate crystals in the proximal tubules were thoroughly investigated. Oxalate and glycolate levels were not increased in a urine organic acid profile performed using GC-MS and primary hyperoxaluria was excluded. Urine oxalate to creatinine ratio was $28 \mu \mathrm{mol} / \mathrm{mmol}$ (reference limit 1-38). Plasma oxalate was demonstrated to be at the upper reference limit at $10 \mu \mathrm{mol} / \mathrm{L}$ $(<10)$. 24-hour urine calcium excretion was not increased at $3.4 \mathrm{mmol} / 24 \mathrm{hr}(2.5-7.5)$.

Due to the initial diagnostic uncertainty, a course of 5 sessions of plasma exchange was completed. The patient required 4 hemodialysis treatments during this course but was independent of dialysis by its completion. Improvement in biochemical and hematological parameters is detailed in Table 1.

On further questioning, the patient eventually admitted preoccupation with health and appearance. She gave a history of having undergone three annual courses of sclerother- apy with Aetoxysclerol single injections for thread veins in her legs. The treatment was carried out in her home country of Poland. The most recent course was four weeks prior to this admission. She had also been taking Vitamin $\mathrm{C}$ in doses exceeding $1100 \mathrm{mg}$ per day for many months (Rutina C and Vitamin C effervescent), as well as multiple other health and beauty supplements for venous insufficiency (Venoruton and Diosminum). Our patient was taking them during her acute illness; however, she discontinued the supplementation of any tablets after the admission to the hospital.

\section{Discussion}

This case describes a young female patient initially suspected to have HUS-TTP, but subsequently discovered to have alternative explanations for the suggestive preliminary findings. This highlights the importance of histopathological confirmations of HUS-TTP. Our patient's renal biopsy in fact showed acute tubular injury, and localised severe tubulointerstitial nephritis, consistent with direct toxic tubular and epithelial damage rather than ischemic/hypovolemic etiology. The presence of widespread numerous oxalate crystals was unexpected. Oxalate deposition is a well-recognised feature of acute tubular injury. However, in this case, the large amount and distribution of the oxalate, including its presence in many tubular epithelial cells, alerted us to the possibility of an additional nonacute mechanism. In keeping with this, we hypothesise that the low-grade tubulointerstitial nephritis seen resulted from damaged tubular epithelium and the consequent release of oxalate crystals into the renal interstitium.

2.1. Oxalate. The clinical context and laboratory data did not support endogenous overproduction of oxalic acid as a possible cause. Neither urinary nor plasma oxalate was elevated. Plasma oxalate was lower $(10 \mu \mathrm{mol} / \mathrm{L})$ than in primary hyperoxaluria type I and II $(>80 \mu \mathrm{mol} / \mathrm{L})$ [2].

It is recognised that the oxalate levels both in plasma and urine were measured on day 10 , after 4 courses of plasma exchange and 5 courses of hemodialysis. Oxalate removal might be enhanced during aggressive dialysis that may result in a prompt recovery of renal function [3]. Oxalate, and its acid form-oxalic acid, derive primarily from three sources: the diet, fungi such as Aspergillus and Penicillium and from human metabolism. Foods especially high in oxalates include spinach, beets, chocolate, peanuts, wheat bran, tea, cashews, pecans, almonds, and berries. Dietary oxalate accounts for $10-20 \%$ of the oxalate excreted in the urine [4]. Our patient was consuming these foods very occasionally, thus it, was unlikely she was ingesting oxalates in excessive amounts.

The etiology of oxalate deposition in the kidneys is probably multifactorial in this patient. Chronic exposure to both very large doses of vitamin $\mathrm{C}$ and the ethylene glycol derivative (used as the sclerosing agent) may both contribute to oxalate deposition. Interestingly, secondary oxalosis due to excessive ingestion of vitamin $\mathrm{C}$ was previously described in patients with acute renal failure who were undergoing hemodialysis [3]. 
TABLE 1: Biochemical and hematological parameters during admission.

\begin{tabular}{|c|c|c|c|c|c|c|}
\hline $\begin{array}{l}\text { Day of in } \\
\text { hospital stay }\end{array}$ & $\begin{array}{c}\text { Creatinine } \\
55-100 \mu \mathrm{mol} / \mathrm{L}\end{array}$ & $\begin{array}{c}\mathrm{Hb} \\
11.5-16.5 \mathrm{~g} / \mathrm{dL}\end{array}$ & $\begin{array}{c}\text { LDH (U/L) } \\
(220-450)\end{array}$ & $\begin{array}{l}\text { Platelets } \times 10^{-9} / \mathrm{L} \\
\quad(150-450)\end{array}$ & Blood film & $\begin{array}{l}\text { Plasma exchange (PE) } \\
\text { or hemodialysis (HD) }\end{array}$ \\
\hline 1 & 1815 & 6.3 & 2205 & 84 & & $\mathrm{HD}(1)$ \\
\hline 2 & 1124 & 9.0 & 2039 & 127 & & PE (1) \\
\hline 2 & 881 & 8.8 & 726 & 112 & & HD (2) \\
\hline 3 & 615 & 8.7 & 615 & 140 & & PE (2) HD (3) \\
\hline 4 & 617 & 7.8 & & & $\begin{array}{l}\text { Poikilocytes, } \\
\text { polychromasia, } \\
\text { acanthocytes }\end{array}$ & PE (3) \\
\hline 7 & 730 & 8.8 & 639 & 241 & $\begin{array}{l}\text { Acanthocytes, } \\
\text { polychromasia, } \\
\text { helmet cells, red } \\
\text { cell fragments } \\
\text { (8\% of RBC) }\end{array}$ & $\mathrm{HD}(4)$ \\
\hline 7 & 302 & 8.8 & 611 & 261 & & PE (4) \\
\hline 8 & 340 & 10 & 573 & 261 & $\begin{array}{l}\text { Occasional } \\
\text { schistocyte }\end{array}$ & Biopsy \\
\hline 9 & 308 & 9.0 & 613 & 230 & $\begin{array}{c}\text { Approximately } \\
6-8 \text { fragmented } \\
\text { cells per } \\
\text { high-power field } \\
\text { seen }\end{array}$ & PE (5) \\
\hline 10 & 255 & 10.2 & 694 & 296 & $\begin{array}{l}\text { 3-4 fragments } \\
\text { per high-power } \\
\text { field }\end{array}$ & \\
\hline 18 & 124 & 10.0 & 488 & 261 & $\begin{array}{l}\text { No fragmented } \\
\text { cells }\end{array}$ & \\
\hline
\end{tabular}

The resolution of creatinine, hemoglobin, lactate dehydrogenase, thrombocytopenia and fragmented cells on blood film, with plasma exchange and hemodialysis courses over a period of 18 days of in hospital stay. HD: hemodialysis, PE: plasma exchange.

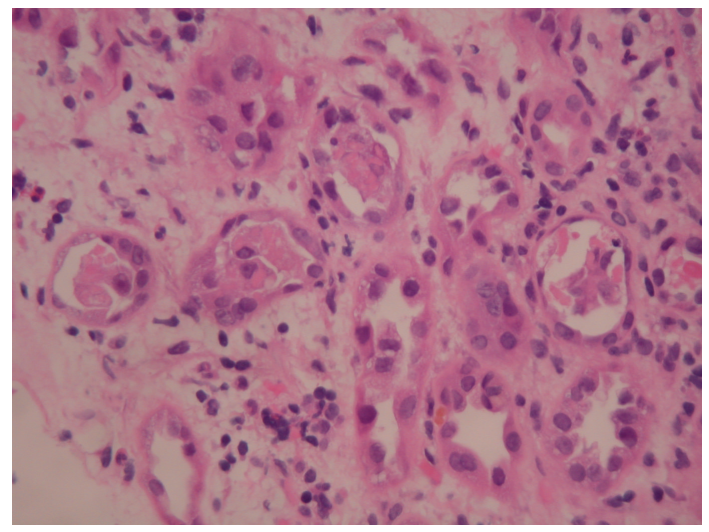

(a)

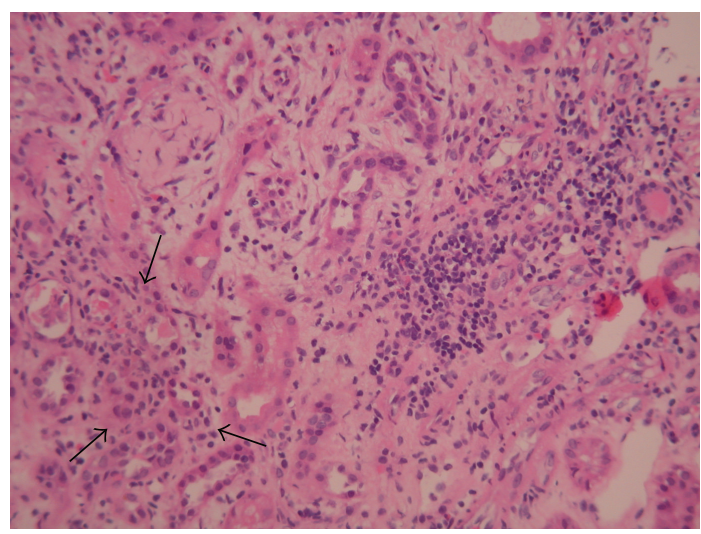

(b)

FIgURE 1: (a) Renal biopsy on hospital day 8 demonstrating focal marked acute tubular injury with cell sloughing seen in the tubular lumena (hematoxylin-eosin, X400). (b) Renal biopsy demonstrating tubulointerstitial nephritis; mild oedema and a focal chronic inflammatory infiltrate (arrows) present with some evidence of acute tubular injury. Cellular and granular cast formation (at left) (hematoxylin-eosin, $\mathrm{X} 200)$.

We hypothesise that oxalate crystals were chronically deposited in the renal tubules and that it might have impaired the patient's ability to cope with dehydration during an episode of vomiting and diarrhoea. The vomiting may have been triggered by gastritis that is supported by gastroscopy findings. Vomiting and low-grade diarrhea-associated with gastritis triggered hypovolemia-associated renal dysfunction.

Vitamin C is a water-soluble vitamin, and dietary excess is eliminated by the kidney via filtration and active tubular resorption. The daily requirement is around $75 \mathrm{mg}$ for 


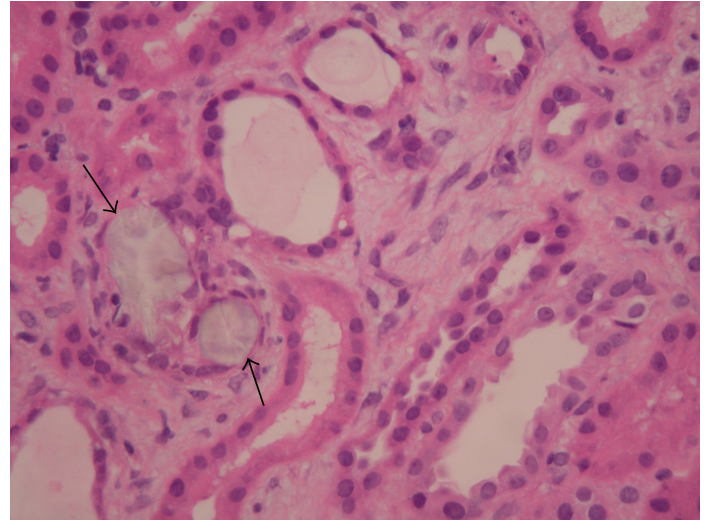

(a)

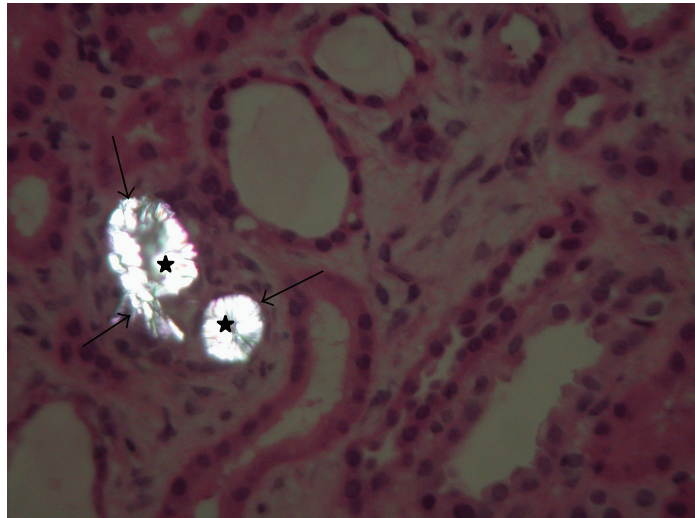

(b)

Figure 2: (a) Oxalate crystals (arrows) in tubular epithelium and lumena under normal light (Original magnification X400). (b) Calcium oxalate crystals $(\star)$ in tubular epithelium and lumena under polarised light (Original magnification X400).

a woman and $90 \mathrm{mg}$ for a man [5]. Its half life is approximately 20 days, and it breaks down to form oxalates in vivo. A number of studies have investigated vitamin C metabolism and hyperoxaluric nephropathy. It has been described in various case reports that vitamin $\mathrm{C}$ in doses of up to $4000 \mathrm{mg}$ a day can induce hyperoxaluric nephropathy and progressive renal failure [6]. Rathi et al. [7] described glomerular and interstitial fibrosis, associated with excessive vitamin C intake, particularly in the presence of dehydration, an oxalate-rich diet, or metabolic acidosis Vitamin Cinduced oxalate nephropathy can be a late diagnosis as individuals may take multivitamin supplements purchased over the counter on top of dietary sources vitamin C [7]. Oxalosis secondary to Vitamin $\mathrm{C}$ administration has been previously reported in patients with acute renal failure who are undergoing hemodialysis [8].

Vitamin C administered in excess ( $\geq 1 \mathrm{~g}$ ) may also cause a hemolytic anemia as a consequence of reducing activity of ascorbic acid on red blood cells. This effect has been noted in patients with Glucose-6-Phosphate Dehydrogenase (G-6$\mathrm{PD}$ ) deficiency administered with intravenous or oral dose of ascorbic acid [9-11]. We are not aware of G-6-PD status in our patient.

The role of ethylene glycol derivatives is less clear. Aetoxysclerol is characterized by its spasmogenic action on veins. The sclerosant effects of polidocanol are by causing concentration-dependent differential cell injury [12]. According to the manufacturer's information, it is used in concentrations between 0.3 and $0.6 \%$ to treat large varicose veins or uncomplicated thread veins. It is usually injected intravenously in concentrations of $0.5-1 \mathrm{~mL} / \mathrm{kg}$, and the maximum recommended volume per treatment session is $10 \mathrm{~mL}$. By comparison, $0.1 \mathrm{~mL} / \mathrm{kg}$ of pure ethylene glycol may result in potentially toxic levels. Aetoxysclerol injections contain polidocanol, an ethylene glycol derivative that is converted to oxalic acid and is reported to have a low risk of complications [13-16]. It has not been shown to have a direct effect on kidneys.

The number, volume, and frequency of sclerosing agent injections received by the patient were not in excess of the manufacturer's recommendations (one injection once a year for three consecutive years). The half life of ethylene glycol is 3-6 hours, so four weeks after the last injection acute ethylene glycol toxicity was not suspected. Nevertheless, the previous exposure to ethylene glycol metabolites may have predisposed her to oxalate deposition in the kidneys.

Although vitamin C and ethylene glycol are two possible explanations of oxalate deposits in the kidney, secondary hyperoxaluria can be also acquired from enteric causes. After a small bowel bypass, calcium complexes with poorly absorbed fatty acids and leaves behind excess unbound oxalate for absorption [6]. This mechanism would explain the enteric hyperoxaluria in chronic diarrhoea and malabsorption. If coexisting, malabsorption, and high-dose vitamin $\mathrm{C}$ could potentiate the hyperoxaluria induced by each other. However, although our patient had diarrhoea for 2 days prior to the admission to the hospital, the episodic duration of symptoms would exclude the enteric hyperoxaluria as a cause of calcium oxalates deposits in the kidney.

The hematological picture is unlikely to have been a direct consequence of uremia. Brain et al. (1967) reported that the onset of microangiopathic hemolytic anemia always preceded the appearance of uremia both in pregnant and not pregnant women [17]. In our patient, it is difficult to establish if microangiopathic hemolytic anemia preceded the uremia. Thus other causes of microangiopathic hemolytic anemia have been considered. Drug-induced oral contraceptive pill-induced hemolysis is one possibility. Our patient has been on Yasmin (ethinylestradiol and drospirenone) for a few months, followed by Microgynon (ethinylestradiol and levonorgestrel) for 3 months prior to the acute presentation. In the previously described cases, hemolytic uremic syndrome was associated with positive steroidal antihormones antibodies [18-20]. However, renal histopathologic changes in postpill hemolytic-uremic syndrome were considered compatible with malignant nephrosclerosis or with thrombotic microangiopathy $[18,19]$, rather than acute tubular injury and oxalate crystals deposits in renal tubules lumina. Additionally, vitamin $\mathrm{C}$ at the dose of $1 \mathrm{~g}$ taken for 7 days has been shown to induce unintentionally high plasma 
concentrations of ethinylestradiol as the two substances compete for sulfation in the gut wall, and the vitamin $\mathrm{C}$ interferes with conversion of ethinyl-estradiol (EE2) to its sulphates [21-23]. As our patient has been taking both vitamin $\mathrm{C}$ and oral contraceptive pill regularly for the three months prior to the sickness, we may hypothesise that the acute presentation was an effect of enhanced pill potential and the drug induction of hemolytic anemia.

The absence of underlying renal disease prior to the admission to the hospital excludes the hypothesis that vomiting and diarrhoea were a consequence of chronic renal disease. The findings of acute tubular injury are most likely related to dehydration and renal hypoperfusion in the setting of vomiting and diarrhoea. It is likely that secondary oxalosis might have resulted from increased vitamin $\mathrm{C}$ ingestion, oxalates accumulation, and reduced excretion in renal insufficiency. Recovery of renal function was enhanced by the removal of oxalate with intense dialysis and by the decrease in oxalate production by limiting the amount of vitamin $\mathrm{C}$ supplementation.

\section{Conclusion}

The acute tubular injury that this patient developed was most likely related to dehydration and renal hypoperfusion caused by vomiting and diarrhoea. The extensive calcium oxalate deposition found in the kidneys might have been the result of chronic, excessive vitamin $\mathrm{C}$ intake and perhaps exposure to ethylene glycol derivatives as part of cosmetic sclerotherapy. Although both compounds may contribute to the oxalate formation, it is likely that oxalate deposits were an incidental finding that coincided with hemolytic anemia and acute tubular injury. Renal recovery may have been delayed by the presence of oxalate deposits.

\section{References}

[1] A. A. Kaplan, "A simple and accurate method for prescribing plasma exchange," ASAIO Transactions, vol. 36, no. 3, pp. M597-M599, 1990.

[2] C. Lefaucheur, G. Hill, C. Amrein et al., "Acute oxalate nephropathy: a new etiology for acute renal failure following nonrenal solid organ transplantation," American Journal of Transplantation, vol. 6, no. 10, pp. 2516-2521, 2006.

[3] A. M. Alkhunaizi and L. Chan, "Secondary oxalosis: a cause of delayed recovery of renal function in the setting of acute renal failure," Journal of the American Society of Nephrology, vol. 7, no. 11 , pp. 2320-2326, 1996.

[4] R. P. Holmes, H. O. Goodman, and D. G. Assimos, "Contribution of dietary oxalate to urinary oxalate excretion," Kidney International, vol. 59, no. 1, pp. 270-276, 2001.

[5] National Academy of Sciences, Dietary Reference Intakes: Recommended Intakes for Individuals, Food and Nutrition Board, Institute of Medicine, Washington, DC, USA, 2000.

[6] S. H. Nasr, Y. Kashtanova, V. Levchuk, and G. S. Markowitz, "Secondary oxalosis due to excess vitamin C intake," Kidney International, vol. 70, no. 10, p. 1672, 2006.

[7] S. Rathi, W. Kern, and K. H. Lau, "Vitamin C-induced hyperoxaluria causing reversible tubulointerstitial nephritis and chronic renal failure: a case report," Journal of Medical Case Reports, vol. 1, article 155, 2007.
[8] S. Mashour, J. F. Turner, and R. Merrell, "Acute renal failure, oxalosis, and vitamin $\mathrm{C}$ supplementation: a case report and review of the literature," Chest, vol. 118, no. 2, pp. 561-563, 2000 .

[9] J. Mehta, S. Singhal, and B. Mehta, "Ascorbic-acid-induced haemolysis in G-6-PD deficiency," The Lancet, vol. 336, no. 8720, p. 944, 1990.

[10] N. Iwamoto, T. Kawaguchi, K. Horikawa et al., "Haemolysis induced by ascorbic acid in paroxysmal nocturnal haemoglobinuria," The Lancet, vol. 343, no. 8893, p. 357, 1994.

[11] D. C. Rees, H. Kelsey, J. D. M. Richards, and D. C. Rees, "Acute haemolysis induced by high dose ascorbic acid in glucose-6phosphate dehydrogenase deficiency," British Medical Journal, vol. 306, no. 6881, pp. 841-842, 1993.

[12] D. M. Eckmann, "Polidocanol for endovenous microfoam sclerosant therapy," Expert Opinion on Investigational Drugs, vol. 18, no. 12, pp. 1919-1927, 2009.

[13] P. Conrad, G. M. Malouf, M. C. Stacey, and H. A. M. Neumann, "The Australian polidocanol (aethoxysklerol) study: results at 2 years," Dermatologic Surgery, vol. 21, no. 4, pp. 334$338,1995$.

[14] C. Grosse-Siestrup, V. Unger, J. Pfeffer et al., "Hepatotoxic effects of polidocanol in a model of autologously perfused porcine livers," Archives of Toxicology, vol. 78, no. 12, pp. 697705, 2004.

[15] T. Yamaki, K. Sasaki, and M. Nozaki, "Color duplex-guided sclerotherapy for the treatment of venous malformations," Dermatologic Surgery, vol. 26, no. 4, pp. 323-328, 2000.

[16] J. Guex, "Complications of sclerotherapy: an update," Dermatologic Surgery, vol. 36, supplement 2, pp. 1056-1063, 2010.

[17] M. C. Brain, K. B. Kuah, and H. G. Dixon, "Heparin treatment of haemolysis and thrombocytopenia in pre-eclampsia," The Journal of Obstetrics and Gynaecology of the British Commonwealth, vol. 74, no. 5, pp. 702-711, 1967.

[18] H. Tobon, "Malignant hypertension, uremia and hemolytic anemia in a patient on oral contraceptives," Obstetrics and Gynecology, vol. 40, no. 5, pp. 681-685, 1972.

[19] C. B. Brown, A. R. Clarkson, and J. S. Robson, "Haemolytic uraemic syndrome in women taking oral contraceptives," The Lancet, vol. 1, no. 7818, pp. 1479-1481, 1973.

[20] F. Schillinger, R. Montagnac, P. Birembaut, and C. Hopfner, "Hemolytic uremic syndrome following oral contraceptives," Revue Francaise de Gynecologie et d'Obstetrique, vol. 81, no. 12, pp. 721-725, 1986.

[21] M. H. Briggs, "Megadose vitamine $\mathrm{C}$ and metabolic effects of the pill," British Medical Journal, vol. 283, no. 6305, p. 1547, 1981.

[22] D. Back and L. M. Orme, "Pharmacokinetic drug interactions with oral contraceptives," Clinical Pharmacokinetics, vol. 18, no. 6, pp. 472-484, 1990.

[23] G. M. Shenfield, "Oral contraceptives: are drug interactions of clinical significance?” Drug Safety, vol. 9, no. 1, pp. 21-37, 1993. 


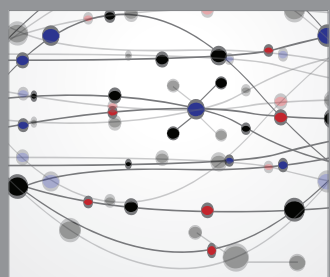

The Scientific World Journal
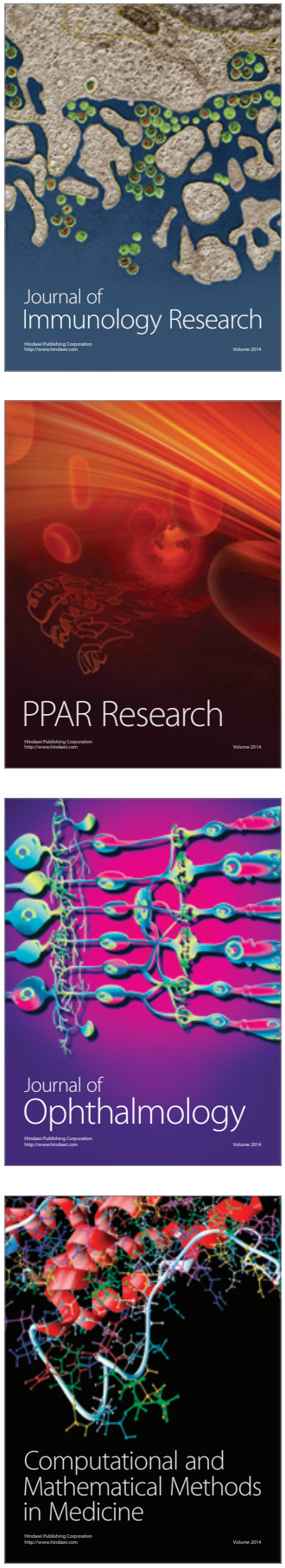

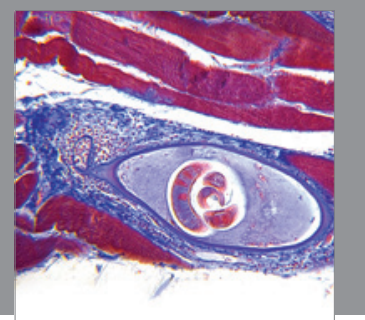

Gastroenterology

Research and Practice
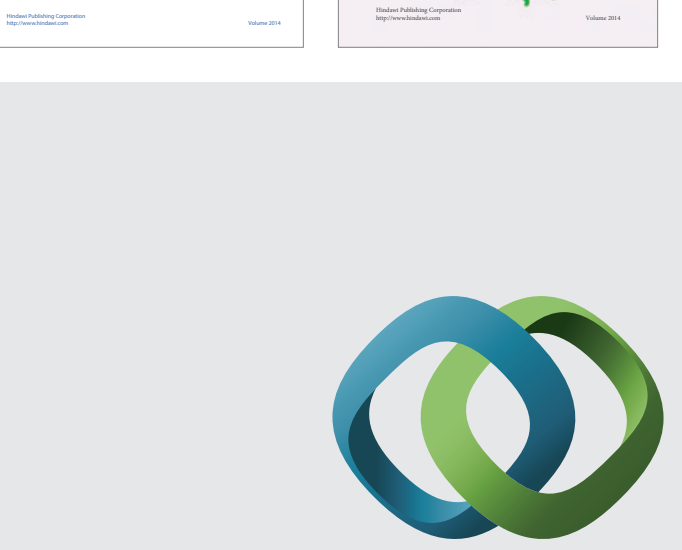

\section{Hindawi}

Submit your manuscripts at

http://www.hindawi.com
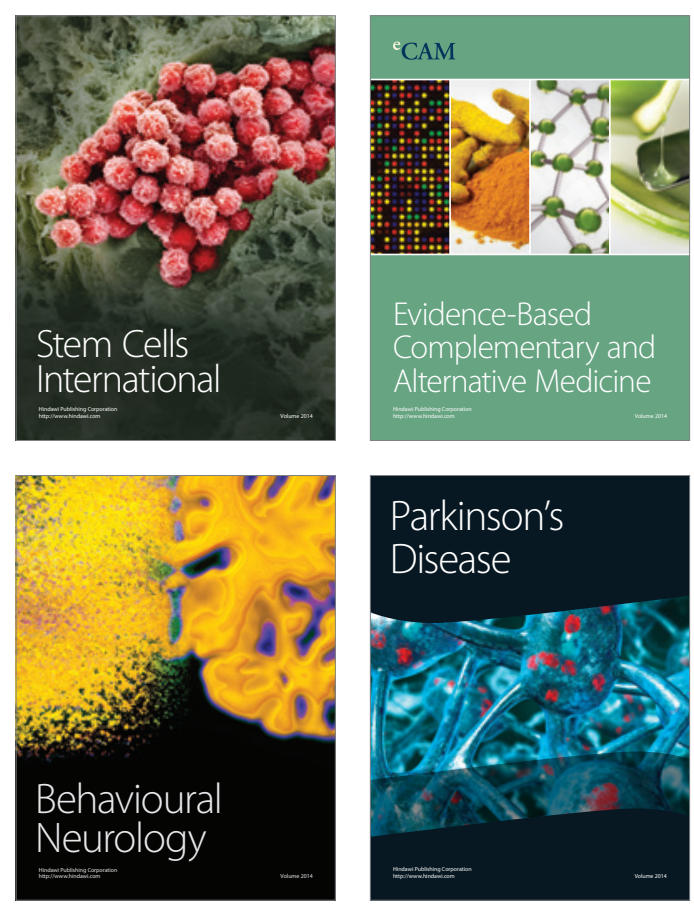

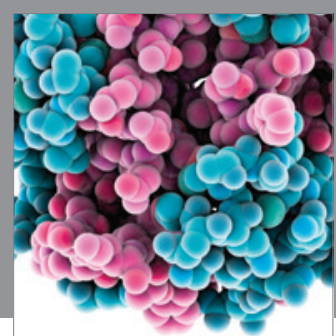

Journal of
Diabetes Research

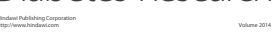

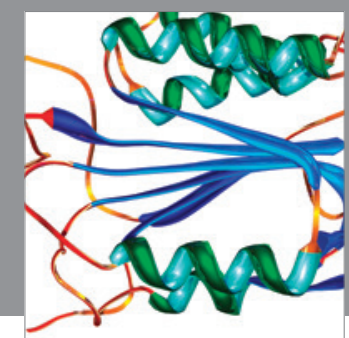

Disease Markers
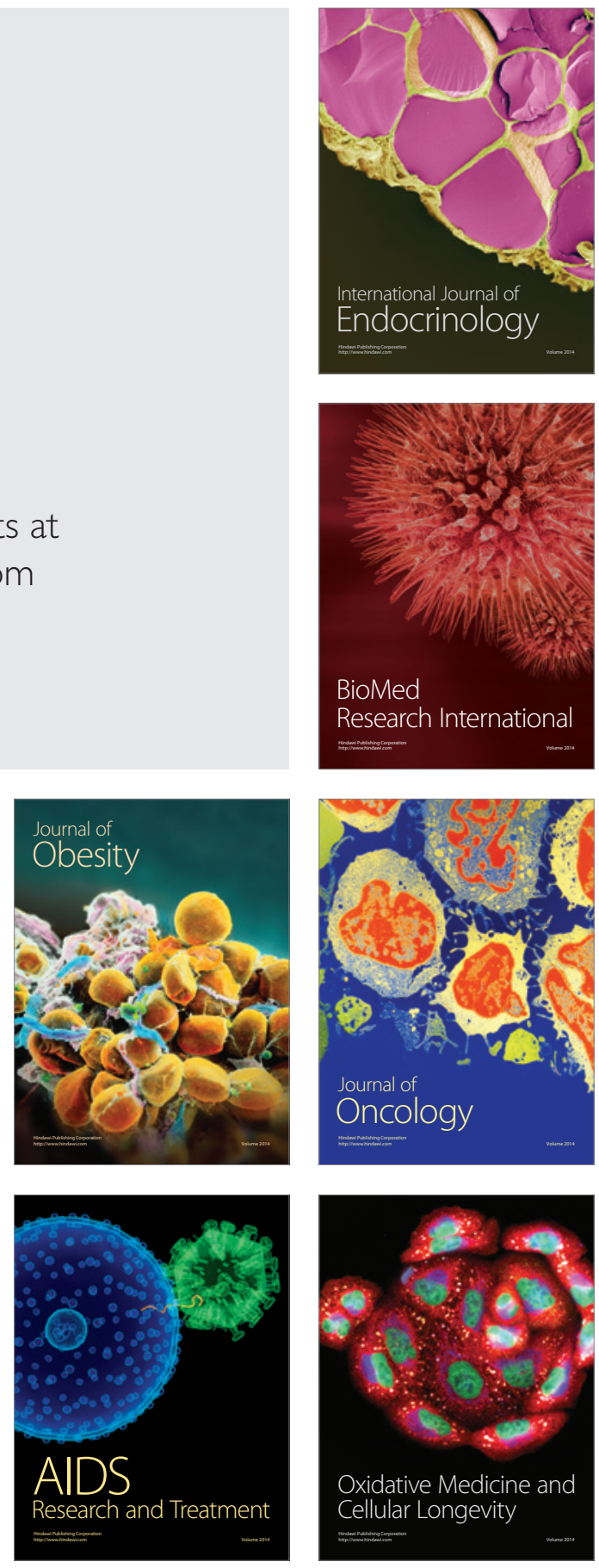